\title{
Avaliação das propriedades do concreto devido à incorporação de lodo de estação de tratamento de água
}

\author{
Evaluation of concrete properties due to \\ the incorporation of sludge from \\ Water Treatment Plant
} Nathann Francisco Tafarel ${ }^{1}$, Gustavo Macioski ${ }^{1}$, Karina Querne de Carvalho ${ }^{1}$,
André Nagalli ${ }^{1}$, Daiane Cristina de Freitas ${ }^{2}$, Fernando Hermes Passig ${ }^{2}$

\footnotetext{
${ }^{1}$ Laboratório de Saneamento e Meio Ambiente - DACOC/UTFPR CEP: 81.280-340, Curitiba, PR

${ }^{2}$ Laboratório de Tratamento de Água Residuária - DAQBI/UTFPR CEP: 81.280-340, Curitiba, PR e-mail:nf.tafarel@gmail.com; gmacioski@utfpr.edu.br; kaquerne@utfpr.edu.br; nagalli@utfpr.edu.br; daianecris.freitas@gmail.com; fhpassig@utfpr.edu.br
}

\section{RESUMO}

O objetivo deste artigo foi avaliar as propriedades do concreto com adição de diferentes teores de lodo de Estação de Tratamento de Água (ETA), de modo a diminuir este passivo ambiental gerado pelas empresas de saneamento. No presente estudo, foram confeccionados corpos de prova de concreto com teores de $5 \%$ e $10 \%$ de lodo de ETA em substituição à areia. O lodo utilizado na fabricação do concreto foi proveniente de uma ETA, responsável pelo tratamento de água de parte de Curitiba, na qual é utilizado sulfato de alumínio como coagulante. Primeiramente foi feita caracterização físico-química do lodo coletado com determinação de pH, temperatura, turbidez, DQO, ST, teor de umidade e massa específica. Em seguida, foram moldados corpos de prova com dimensões de $(10 \times 20) \mathrm{cm}$ e com os respectivos teores de lodo a serem incorporados e avaliadas as propriedades no estado endurecido do concreto: resistência à compressão, resistência à tração por compressão axial e absorção de água. Considerando os resultados obtidos, apenas as amostras com $5 \%$ de lodo de ETA apresentaram condições satisfatórias de resistência à compressão axial quando comparadas ao concreto referência, com 15,5 MPa aos 28 dias e perda de resistência próxima a 11\%. Portanto, o concreto confeccionado com substituição de 5\% de agregado miúdo por lodo de ETA pode ser utilizado com finalidade não estrutural, se consideradas apenas as propriedades mecânicas do material. Estudos como este são fundamentais para criar soluções para os resíduos gerados nas Estações de Tratamento de Água.

Palavras-chave: Resíduos Sólidos. Construção Civil. Reaproveitamento. Resistência. Absorção.

\section{ABSTRACT}

The objective of this paper was to evaluate concrete properties after adding different proportions of sludge from a Water Treatment Plant (WTP), thus decreasing the generation of this environmental pollutant, which is originated by sanitation companies. In the present study, test specimens of concrete containing $5 \%$ and $10 \%$ of sludge from a WTP in substitution of sand, with the reference trace were made. The sludge used for concrete production was from a WTP partially responsible for the water treatment of Curitiba, where aluminum sulphate is used as coagulant. Firstly, a physical-chemical characterization of the collected sludge was performed determining the $\mathrm{pH}$, analyzing the temperature, turbidity, COD, TS, humidity proportions and specific mass. Posteriorly, test specimens were made with dimensions of $(10 \times 20) \mathrm{cm}$ and with the respective content of sludge to be incorporated. It was also evaluated the concrete hardened properties: compressive strength, tension strength of cylindrical specimens submit to diametrical compression and absorption. Considering the results, only sample with 5\% of WTP sludge showed satisfactory conditions of resistance and axial compression when compared with the reference, with $15.5 \mathrm{MPa}$ at 28 days and resistance loss around $11 \%$. Therefore, the concrete made with the substitution of $5 \%$ of small aggregate may be used for nonstructural finality, considering only the mechanical properties of the material because it is not possible to state about its durability. Studies like this are crucial in order to create solutions for the sludge generated in 
Water Treatment Plants.

Keywords: Solid Wastes. Construction. Reuse. Compressive Strength. Absorption.

\section{INTRODUÇÃO}

O acréscimo da demanda por água tratada tem resultado no aumento anual da quantidade de lodo produzido nas estações de tratamento, o que tem desafiado engenheiros e pesquisadores na busca por métodos e processos de manuseio e disposição deste resíduo $[1,2]$.

Das Estações de Tratamento de Água (ETA) utilizadas no Brasil, cerca de 7.500 são do tipo convencional [3], nas quais é gerado lodo nas etapas de decantação e de filtração - constituído de água, sólidos suspensos e parcela de produtos resultantes da adição de reagentes coagulantes. Normalmente este lodo é disposto em cursos de água próximos, alterando as características do corpo receptor. Contudo, conforme definido na ABNT NBR 10004 (2004) [4], este subproduto gerado é classificado como resíduo sólido e semissólido, sendo obrigatória sua destinação final adequada, prevista na Política Nacional de Resíduos Sólidos (PNRS) Lei $\mathrm{n}^{\mathrm{o}} 12305 / 2010$ [5].

Como são poucas as cidades que dispõem de aterros sanitários, surge preocupação ligada às questões ambientais para destinação final do lodo. Tem-se então um problema de disposição final e necessidade de avaliação de técnicas para seu reaproveitamento de forma a atender às diretrizes, critérios e procedimentos estabelecidos na Política Nacional de Resíduos Sólidos (PNRS) - Lei no 12305/2010 [5], no que concerne ao reaproveitamento de resíduos sólidos.

A gestão adequada deste resíduo é importante, pois o lodo da ETA tem concentrações de alumínio, ferro, matéria orgânica e sólidos que podem causar toxicidade a organismos aquáticos, alterações biológicas, assoreamento e consequentemente transbordamento de corpos hídricos em épocas de cheias ao serem lançados em corpos hídricos [6,7].

As alternativas de disposição dos lodos de ETA têm sido aterros sanitários, aterros exclusivos, disposição em áreas de reflorestamento e áreas agrícolas e utilização no controle de sulfetos em sistemas de coleta, transporte e tratamento de esgotos [8]. Uma alternativa encontrada para reaproveitamento do lodo está na construção civil por meio de sua incorporação nos componentes de fabricação do concreto. Estudos têm sido desenvolvidos com adição em até $10 \%$ do lodo da ETA em argamassas e produtos com fins não estruturais em substituição à areia $[9,10]$. A incorporação deste tipo de lodo em argila foi avaliada por [11] para produção de uma célula vítrico-cerâmica com o objetivo de mitigar problemas ambientais associados.

A incorporação do lodo na fabricação do concreto favorece a construção civil e o ambiente devido à diminuição da quantidade de resíduo lançada no ambiente e da extração de matéria-prima, reduzindo impactos ambientais.

Dentro deste contexto, o objetivo geral deste trabalho foi avaliar a influência da adição de diferentes teores de lodo de ETA em substituição parcial de agregado miúdo nas propriedades no estado endurecido do concreto convencional - resistência à compressão, à tração por compressão diametral e absorção de água por imersão, visando a fabricação de blocos intertravados para pavimento.

\section{MATERIAIS E MÉTODOS}

Nesta seção são apresentadas as metodologias empregadas para e coleta de amostras do lodo, caracterização físico-química dos materiais, dosagem do concreto e caracterização das propriedades do concreto no estado endurecido.

\subsection{Descrição da ETA e método de coleta}

Na Estação de Tratamento de Água deste estudo são tratados aproximadamente $2000 \mathrm{~L} / \mathrm{s}$ de água para abastecimento de parte do município de Curitiba, estado do Paraná. Na ETA o tratamento da água se dá por coagulação, floculação, decantação, filtração, desinfecção e fluoretação, configurando ciclo completo [12].

A geração diária do lodo na ETA é de 12 toneladas provenientes da água da lavagem dos filtros e dos decantadores com teor de sólidos de 2\%. De acordo com HOPPEN [9], a geração mensal de lodo é de 360 toneladas e seu adensamento é feito com centrífuga decanter e o polímero aniônico Flonex ${ }^{\circledR}$. Como forma de disposição final, o lodo é misturado com resíduos da construção civil para recuperação de áreas degradadas ou destinado a aterros sanitários. A geração diária do lodo na ETA é de 12 toneladas provenientes da água da com teor de sólidos de $2 \%$.

Para desenvolvimento deste trabalho foram coletadas amostras do lodo da descarga de um dos decan- 
tadores e do lodo adensado após a etapa da centrifugação. As amostras de lodo coletadas foram armazenadas separadamente em recipientes plásticos de 60 L. Também foram coletadas amostras do lodo com e sem adição de polímeros para posterior comparação das características físico-químicas.

\subsection{Caracterização físico-química do lodo de ETA}

A caracterização físico-química das amostras de lodo foi realizada por meio de determinação dos parâmetros temperatura, $\mathrm{pH}$, turbidez, teor de umidade, massa específica aparente, demanda química de oxigênio (DQO) e sólidos totais (ST). As análises para o lodo de descarga (in natura) e para o lodo adensado seguiram metodologias descritas no Standard Methods for the Examination of Water and Wastewater [13] em triplicata conforme apresentado na Tabela 1.

Tabela 1: Parâmetros, métodos e referências usados na caracterização físico-química do lodo de ETA.

\begin{tabular}{ccc}
\hline PARÂMETRO & N. DO MÉTODO & REFERÊNCIA \\
\hline Temperatura $\left({ }^{\circ} \mathrm{C}\right)$ & 4500 A e B & $\begin{array}{c}\text { Standard Methods for the Examination } \\
\text { of Water and Wastewater }[13]\end{array}$ \\
\hline $\mathrm{pH}$ & $4500 \mathrm{~A}$ e B & $\begin{array}{c}\text { Standard Methods for the Examination } \\
\text { of Water and Wastewater }[13]\end{array}$ \\
\hline Turbidez $(\mathrm{UNT})$ & Part. 2130 B & $\begin{array}{c}\text { Standard Methods for the Examination } \\
\text { of Water and Wastewater }[13]\end{array}$ \\
\hline Teor de umidade $(\%)$ & - & ABNT NBR 6457 (1986) [14] \\
\hline Massa específica aparente $\left(\mathrm{g} / \mathrm{cm}^{3}\right)$ & - & Adaptado da ABNT NBR 12076 (1991) [15] \\
\hline DQO (mg/L) & $5220 \mathrm{D}$ & $\begin{array}{c}\text { Standard Methods for the Examination } \\
\text { of Water and Wastewater }[13]\end{array}$ \\
\hline ST $(\mathrm{mg} / \mathrm{L})$ & $2540 \mathrm{~B}, \mathrm{C}, \mathrm{D}$ e E & $\begin{array}{c}\text { Standard Methods for the Examination } \\
\text { of Water and Wastewater }[13]\end{array}$ \\
\hline
\end{tabular}

Na determinação da turbidez foi feita diluição do lodo na proporção de 1:10 em água destilada para possibilitar a leitura posterior no turbidímetro devido à concentração de sólidos presentes nas amostras. $\mathrm{Na}$ determinação da DQO foi feita diluição do lodo na proporção de 1:2 em água destilada para realizar leitura do comprimento de onda no espectrofotômetro Hach, modelo DR 5000 devido à concentração de matéria orgânica e sólidos presentes nas amostras. Não foi possível realizar a determinação do teor de umidade do lodo de descarga, pois o material apresentava menor concentração de sólidos suspensos na água, sendo suficiente a determinação dos sólidos totais (ST) para caracterização da amostra.

\subsection{Caracterização dos materiais e dosagem do concreto}

Para os concretos dosados em laboratório foi utilizado o cimento Portland CPV-ARI da marca Itambé com adição de até $5 \%$ de fíler calcário e sem adição de pozolanas em sua composição. As características físicoquímicas e a massa específica de $3,09 \mathrm{~g} / \mathrm{cm}^{3}$ destes materiais foram fornecidas pelo fabricante. Na Tabela 2 são apresentadas as características físico-químicas do cimento adotado.

Tabela 2: Características Físico-Químicas do Cimento CPV-ARI.

\begin{tabular}{|c|c|}
\hline CARACTERÍSTICAS & VALOR \\
\hline \multicolumn{2}{|l|}{ FÍSICAS } \\
\hline Expansibilidade à quente $(\mathrm{mm})$ & 0,25 \\
\hline Tempo de Pega (h:min) - Início e fim & 03:24 a 04:02 \\
\hline Consistência Normal (\%) & 29,3 \\
\hline Área superficial Blaine $\left(\mathrm{cm}^{2} / \mathrm{g}\right)$ & 3.994 \\
\hline Resíduo \#200 (\%) & 0,05 \\
\hline Resíduo \#325 (\%) & 0,95 \\
\hline
\end{tabular}




\begin{tabular}{c|c}
\hline Resistência à Compressão - 28 dias (MPa) & 52,3 \\
\hline \multicolumn{2}{c}{ QUÍMICAS } \\
\hline Óxidos totais (\%) & 94,74 \\
\hline Perda ao Fogo (\%) & 3,25 \\
\hline CaO Livre (\%) & 0,79 \\
\hline Resíduo Insolúvel (\%) & 0,74 \\
\hline Equivalente Alcalino (\%) & 0,65 \\
\hline
\end{tabular}

Foram utilizados agregado miúdo de origem natural e brita 0 (pedrisco) de origem granítica. As curvas granulométricas destes materiais são apresentadas na Figura 1.

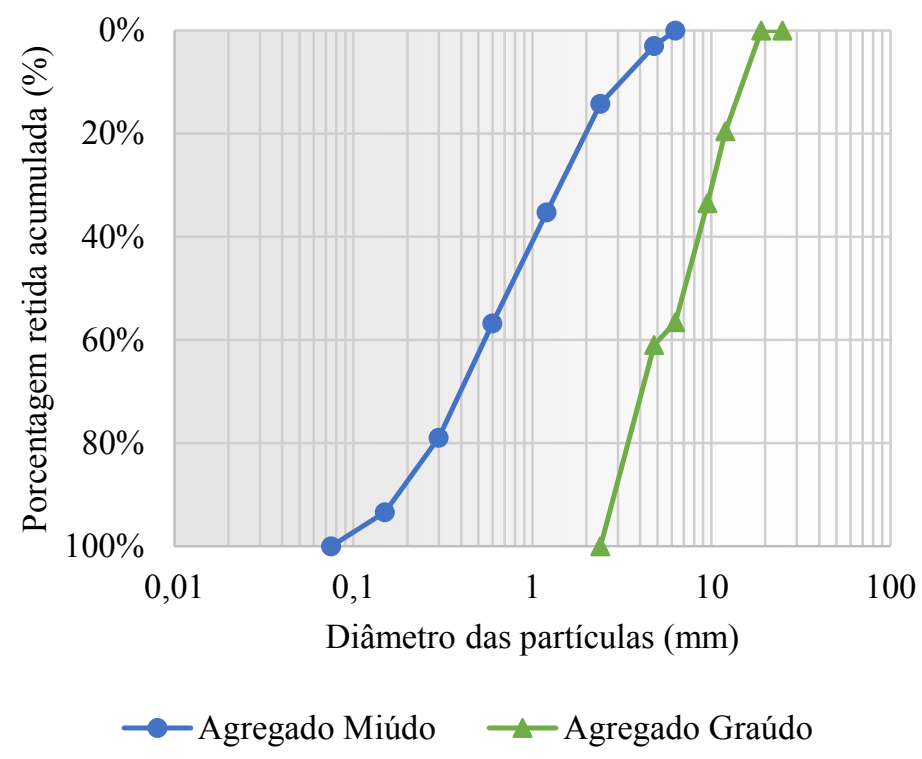

Figura 1: Distribuição granulométrica dos agregados utilizados

A dosagem do concreto foi baseada no método brasileiro ABCP/ACI, adaptado da American Concrete Institute para resistência característica de $15 \mathrm{MPa}$ e abatimento de $100 \mathrm{~mm}$, resultando no traço de referência 1: 1,69: 2,89: 0,5 (cimento: agregado miúdo: agregado graúdo: relação água/cimento). Não foi utilizado qualquer aditivo químico ou adição mineral e o abatimento foi mantido mesmo com a adição do lodo, não necessitando de ajustes.

Os resultados dos ensaios de caracterização dos agregados miúdo e graúdo e suas respectivas metodologias são apresentados na Tabela 3.

Tabela 3: Caracterização físico-química dos agregados miúdo e graúdo utilizados.

\begin{tabular}{cccc}
\hline ENSAIO & \multicolumn{1}{c}{ MÉTODO } & AGREGADO MIÚDO AGREGADO GRAÚDO \\
\hline Massa específica aparente $\left(\mathrm{g} / \mathrm{cm}^{3}\right)$ & $\begin{array}{c}\text { ABNT NBR NM 52 (2009) [16] } \\
\text { ABNT NBR NM 53 (2009) [17] }\end{array}$ & 2,66 & 2,70 \\
\hline Massa Unitária $\left(\mathrm{g} / \mathrm{cm}^{3}\right)$ & ABNT NBR NM 45 (2003) [18] & 1,35 & 1,67 \\
\hline Material Pulverulento (\%) & ABNT NBR NM 46 (2003) [19] & 3,20 & 2,70 \\
\hline DMC (mm) & ABNT NBR 248 (2003) [20] & 4,8 & 9,5 \\
\hline Módulo de finura & ABNT NBR 248 (2003) [20] & 2,6 & 1,79 \\
\hline
\end{tabular}

Foi realizada substituição em volume do agregado miúdo por lodo de ETA nas proporções de 5 e $10 \%$. 
O lodo foi adicionado úmido e a quantidade de água da mistura foi ajustada para manter a relação a/c. Os corpos-de-prova foram confeccionados em moldes metálicos cilíndricos (100 x 200) mm conforme procedimentos da ABNT NBR 5738 (2003) [21]. O desmolde dos corpos-de-prova foi realizado após período de 24 horas e a cura foi realizada em câmara úmida até as datas de ensaio.

\subsection{Propriedades do concreto no estado endurecido}

Para caracterização do concreto no estado endurecido foram realizados ensaios de resistência à compressão aos 7 e 28 dias, conforme procedimentos descritos na ABNT NBR 5739 (2007) [22]. Também foram avaliadas a resistência à tração por compressão axial e absorção de água aos 28 dias, conforme descrito nas normas ABNT NBR 7222 (2011) [23] e ABNT NBR 9778 (2005) [24]. Os rompimentos dos corpos de prova foram realizados em prensa hidráulica EMIC com capacidade de 30 toneladas.

Destaca-se que na ABNT NBR 9781 (2013) [25], na qual são especificados os critérios de controle de qualidade de peças de concreto intertravado para pavimento, são citadas a avaliação da resistência à compressão e a absorção de água do material, além dos ensaios da geometria das peças. Uma vez que este estudo foi realizado visando a aplicação do concreto com incorporação de lodo neste tipo de peça, os ensaios de caracterização realizados foram os mesmos previstos na norma já citada. A resistência à tração, por sua vez, se torna importante pelo esforço de flexão submetido normalmente nas peças intertravadas durante o tráfego de veículos e pessoas, podendo gerar fissuras em sua face inferior, causando penetração de agentes agressivos e redução da durabilidade da peça de concreto.

\subsection{Análise de Dados}

Os dados coletados foram analisados por meio de inferência estatística utilizando o teste paramétrico ANOVA - com nível de confiança de 95\%. Também foi realizada a comparação múltipla de médias por intervalo de confiança, buscando-se diferenças significativas entre as amostras com nível de confiança de $99 \%(3 \sigma)$. Quando observados resultados estatisticamente semelhantes, repetiu-se o teste com nível de confiança de $95 \%(2 \sigma)$. Os dados foram apresentados em gráfico de barras com o erro padrão da média, de forma a permitir observar a tendência central e a variabilidade dos dados amostrais. A correlação linear entre os dados de absorção de água e resistência à compressão foi apresentada em gráfico de dispersão.

\section{RESULTADOS E DISCUSSÃO}

Nesta seção são apresentados os resultados e as discussões acerca da caracterização físico-química do lodo da ETA e da caracterização do concreto com adição de lodo.

\subsection{Caracterização do lodo de ETA}

Os resultados da caracterização do lodo da ETA são apresentados na Tabela 4.

Tabela 4: Parâmetros, métodos e referências usados na caracterização físico-química do lodo de ETA.

\begin{tabular}{ccc}
\hline PARÂMETRO & LODO DE & LODO \\
& DESCARGA & ADENSADO \\
\hline Temperatura $\left({ }^{\circ} \mathrm{C}\right)$ & $22,8 \pm 0,12$ & $23,2 \pm 0,17$ \\
\hline $\mathrm{pH}$ & $6,8 \pm 0,1$ & $6,7 \pm 0,1$ \\
\hline Turbidez $(\mathrm{UNT})$ & $715 \pm 23$ & $1527 \pm 38$ \\
\hline Teor de umidade $(\%)$ & - & $86,4 \pm 0,1$ \\
\hline Massa específica aparente $\left(\mathrm{g} / \mathrm{cm}^{3}\right)$ & $1,24 \pm 0,02$ & $1,24 \pm 0,02$ \\
\hline DQO $(\mathrm{mg} / \mathrm{L})$ & $855 \pm 67$ & $1501 \pm 9,3$ \\
\hline $\mathrm{ST}(\mathrm{mg} / \mathrm{L})$ & $2234 \pm 31$ & $7390 \pm 130$ \\
\hline
\end{tabular}

Ao verificar estes resultados do lodo gerado na estação de tratamento de Curitiba, é possível comparálos com os gerados nas demais estações de tratamento pesquisadas no Brasil e reportados na literatura, bem como com os valores limites especificados nas normas técnicas e resoluções vigentes.

Os valores de $\mathrm{pH}$, próximos da neutralidade, foram similares aos obtidos por PORTELLA et al. [26] de 6,4 a 7,0 que caracterizaram o lodo da mesma estação de tratamento. Como os resultados foram superiores 
a 5,5 e inferiores a 9,0 pode-se utilizar este subproduto na matriz de concreto, conforme descrito na ABNT NBR 159000 (2009) [27].

RICHTER [28] reporta que o lodo de ETA com adição de sulfato de alumínio na etapa de coagulação tem pH variável de 6,0 a 8,0 e TSUTIYA e HIRATA [29] destacam que lodo com pH com valores superiores a 6,5 pode apresentar toxicidade do alumínio, tornando o alumínio disponível para o meio ambiente, com eventuais repercussões ambientais em caso de lançamentos em corpos d'água e/ou solo. É possível notar que os resultados obtidos são similares, não havendo diferença na utilização somente do lodo adensado após a centrifugação para confecção dos corpos-de-prova.

A temperatura variou na faixa de 22,8 a $23,5{ }^{\circ} \mathrm{C}$, com valor médio de $23{ }^{\circ} \mathrm{C}$ para as amostras do lodo adensado e de $22,8^{\circ} \mathrm{C}$ para as amostras do lodo in natura. Estes resultados são similares aos obtidos por BARBOSA et al. [8] de $21,5^{\circ} \mathrm{C}$ a $22,9{ }^{\circ} \mathrm{C}$ no lodo in natura de uma ETA de São Carlos, estado de São Paulo, na qual era utilizado sulfato de alumínio como coagulante. Os valores obtidos neste trabalho estão de acordo com os valores reportados na ABNT NBR 7215 (1997) [30] de 21 a $25^{\circ} \mathrm{C}$ para fabricação de concreto.

Os valores de turbidez variaram de 667 a 743 UNT, com valor médio de 715 UNT nas amostras de lodo in natura e de 1460 a 1590 UNT, com valor médio de 1527 UNT nas amostras de lodo adensado. Estes valores estão de acordo com a faixa reportada por OLIVEIRA [31] de 365 a 2290 UNT para amostras de lodo sedimentado da mesma estação de tratamento.

A DQO variou de 758 a $1513 \mathrm{mg} / \mathrm{L}$, com valor médio de $855 \mathrm{mg} / \mathrm{L}$ nas amostras de lodo in natura e de 1483 a $1508 \mathrm{mg} / \mathrm{L}$, com valor médio de $1501 \mathrm{mg} / \mathrm{L}$ nas amostras de lodo adensado. Estes valores obtidos são superiores ao indicado por OLIVEIRA [31] de $479 \mathrm{mg} / \mathrm{L}$. Segundo esta autora, os resultados são superiores ao valor de $150 \mathrm{mg} / \mathrm{L}$ estabelecido na Portaria $n^{\circ}$ 357/2005 do CONAMA [32] e Resolução $n^{\circ} 001$ da SEMA [33] para lançamento em corpos hídricos receptores. A concentração da matéria orgânica incorporada ao concreto pode influenciar na hidratação do cimento [34], acarretando em maior consumo de água, facilitando a entrada de agentes agressivos, além de comprometer a resistência mecânica do concreto.

As concentrações de ST, STV e STF foram determinadas em amostras do lodo com e sem adição de polímeros. A concentração de ST variou de 2182 a $2232 \mathrm{mg} / \mathrm{L}$, com valor médio de $2234 \mathrm{mg} / \mathrm{L}$ nas amostras do lodo in natura e de 7136 a $7468 \mathrm{mg} / \mathrm{L}$, com média de $7390 \mathrm{mg} / \mathrm{L}$ nas amostras do lodo adensado. Estes valores são similares a faixa verificada por OLIVEIRA [31] de 1672 a $3492 \mathrm{mg} / \mathrm{L}$, com valor médio de $2342 \mathrm{mg} / \mathrm{L}$ para amostras de lodo da mesma ETA. As relações médias de STF/ST e STV/ST resultaram de $51 \%$ e $48 \%$ nas amostras do lodo in natura e adensado, respectivamente. SOARES [34] notou valores de ST, $\mathrm{STF} / \mathrm{ST}$ e STV/ST de $9083 \mathrm{mg} / \mathrm{L}, 67,3 \%$ e 32,7\%, respectivamente, em amostras de lodo in natura de uma ETA na qual é utilizado sulfato de alumínio como coagulante. Os valores obtidos do lodo atendem ao limite de $5000 \mathrm{mg} / \mathrm{L}$ de ST especificado na ABNT NBR NM 137 (1997) [35].

O teor de umidade resultou de $86,47 \pm 0,1 \%$, com valor médio de $86,39 \%$ para o lodo adensado, similar aos obtidos por PORTELLA et al. [27] de 87\% e HOPPEN [10] de 85\% para amostras de lodo da mesma estação de tratamento deste trabalho. A massa específica aparente variou de 1,2 a $1,26 \mathrm{~g} / \mathrm{cm}^{3}$, com valor médio de $1,23 \pm 0,03 \mathrm{~g} / \mathrm{cm}^{3}$ nas amostras do lodo adensado. RICHTER [29] obteve densidade aparente variável de 1,029 a $1,083 \mathrm{~g} / \mathrm{cm}^{3}$, podendo chegar a $1,5 \mathrm{~g} / \mathrm{cm}^{3}$, após a desidratação de lodo com $12 \%$ de teor de sólidos. Estudos realizados com o lodo adensado [34, 36, 37] indicaram valores massa específica real de até $2,58 \mathrm{~g} / \mathrm{cm}^{3}$.

\subsection{Propriedades no estado endurecido dos concretos}

Na Figura 2 são apresentados os resultados da resistência axial sem correção, nos corpos-de-prova sem adição de lodo $(0 \%)$ e com adição de $5 \%$ e $10 \%$ em função da idade do concreto no $7^{\circ}$ e $28^{\circ}$ dia. 


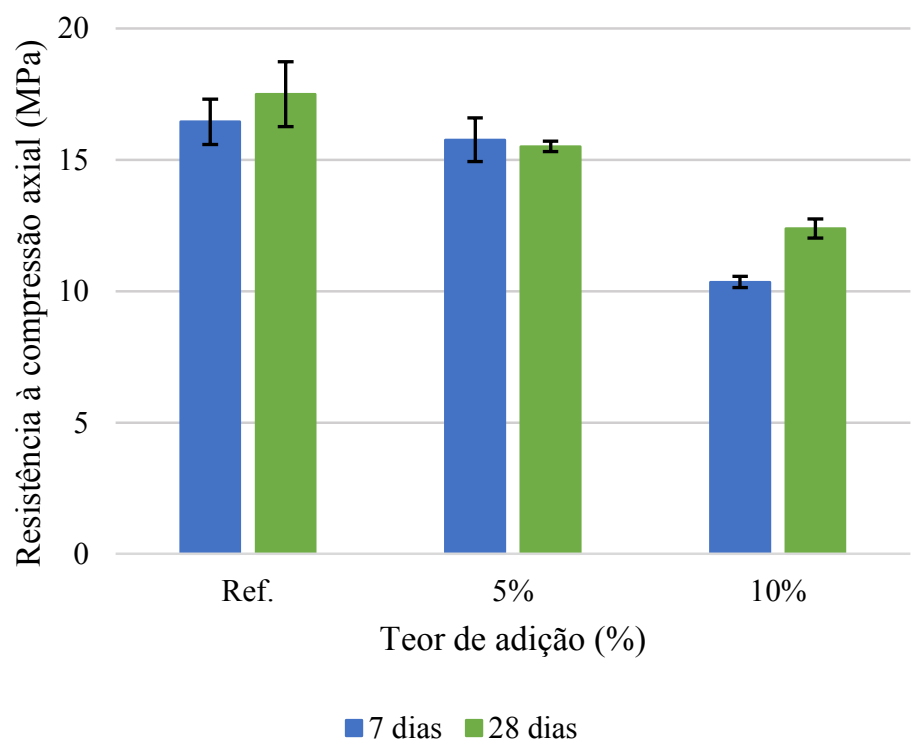

Figura 2: Variação da resistência à compressão axial das amostras de concreto sem e com adição do lodo da ETA

No corpo de prova referência ( $0 \%$ ) foi verificada resistência axial de $16,45 \pm 0,86 \mathrm{MPa}$ no $7^{\circ}$ dia. Foi verificada diminuição da resistência axial em $4,19 \%$ com a incorporação de $5 \%$ de lodo e de $37,08 \%$ do concreto referência com a incorporação de $10 \%$ no $7^{\circ}$ dia. Foi verificada redução significativa (com $99 \%$ de confiabilidade) apenas entre as amostras de referência e com adição de $10 \%$ de lodo. As amostras com $5 \%$ de adição de lodo são estatisticamente iguais àquelas sem adição do material, com nível de confiança de $95 \%$.

A resistência à compressão média reduziu em $11,37 \%$ no corpo de prova com a adição de $5 \%$ de lodo da ETA comparado àquela verificada para o corpo de prova referência $(0 \%)$ no $28^{\circ}$ dia. No corpo de prova com adição de $10 \%$ foi verificada redução da resistência à compressão média em $29,25 \%$ em relação àquela obtida para o corpo de prova de referência $(0 \%)$. Foi verificada diferença estatística significativa (com $99 \%$ de confiabilidade) apenas entre as amostras de referência e com adição de $10 \%$ de lodo.

HOPPEN [11] notou diminuição de $13 \%$ na resistência à compressão com a incorporação de $4 \%$ de lodo, com valores similares no $28^{\circ}$ dia. A diferença nos resultados pode ser explicada pelas diferentes metodologias empregadas, pois HOPPEN [11] realizou vibração nas prensas para moldagem dos corpos-de-prova, enquanto que neste trabalho foram usadas apenas hastes metálicas e moldagem manual.

Segundo TUTIKIAN e HELENE [38] a desvantagem do método ABCP/ACI consiste no fato de que os valores de proporção do traço são tabelados e não contemplam todos os materiais existentes. Ainda assim o método foi eficiente na dosagem do concreto, atingindo o valor de dosagem (15 MPa) embora com erros acima dos admitidos.

Vale destacar ainda que a diferença da resistência observada entre as amostras nos $7^{\circ}$ e $28^{\circ}$ dias foi significativa apenas com a incorporação de $10 \%$ de lodo ( $95 \%$ de probabilidade de resultados diferentes). Este comportamento pode ser explicado pela presença de aditivos químicos e de matéria orgânica que podem alterar o processo de hidratação do cimento Portland, ocasionando aumento do tempo de início de pega e retardando a formação dos compostos hidratados [39].

SALES et al. [40] em seus estudos desenvolveram um compósito leve para concreto utilizando lodo de ETA e resíduos de madeira. Em seus resultados os autores observaram baixa resistência mecânica nos teste à compressão axial.

Foi verificada formação de cristais na superfície externa dos corpos de prova com concreto e incorporação do lodo de ETA no $7^{\circ}$ dia da cura, conforme pode ser visto na Figura 3. 


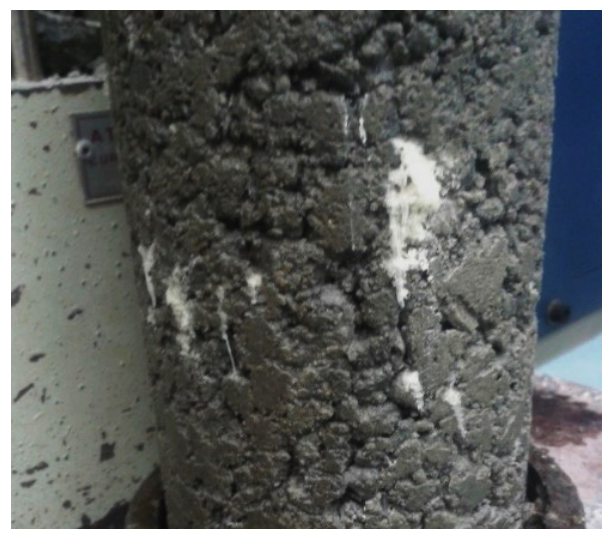

Figura 3: Presença de cristais na superfície externa do corpo de prova com adição de lodo de ETA

De acordo com BROWN [41], uma forma física de ataque de sulfatos ao concreto ocorre com a cristalização dos mesmos. Este tipo de reação é considerada deletéria, o que pode gerar fissuração por expansão dos compostos hidratados, e pode ser mitigada com o uso de pozolanas [42]. Outros aspectos negativos quanto à durabilidade também já foram observados na reciclagem do lodo de ETA em cerâmica argilosa, que deve ser realizada em pequenos percentuais para minimizar seu efeito deletério na qualidade da cerâmica após a queima [43].

Segundo KAKALI et al. [44] o ataque por sulfatos costuma ocorrer pelas propriedades expansivas da etringita (composto hidratado do cimento). Além disso, também é possível observar ataque por sulfatos pela formação da thaumasite, quando presente silicato de cálcio, sulfato e íons carbonato, mesmo em baixa temperatura. Conforme reportado por [45] algumas técnicas comuns podem auxiliar na melhoria da resistência ao ataque de sulfato. Uma delas é reduzir a permeabilidade ao limitar a proporção de água para materiais de cimento, através do uso de materiais complementares de liga, e outra é controlar a quantidade de aluminato no cimento reativo.

Para determinação da resistência à tração por compressão diametral para cada traço foram utilizados os corpos-de-prova com idade de 28 dias. Os resultados médios da resistência à tração por compressão diametral e o erro padrão da média sem incorporação de lodo $(0 \%)$ e com incorporação de $5 \%$ e $10 \%$ são apresentados na Figura 4.

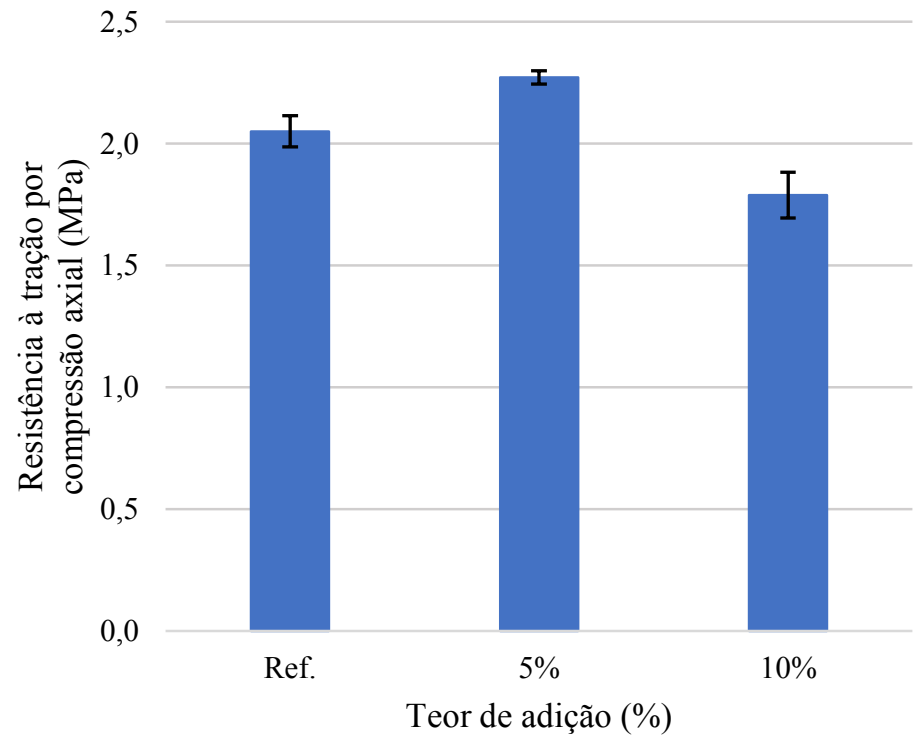

Figura 4: Variação da resistência à tração por compressão diametral de concreto sem e com adição do lodo da ETA

Pode-se verificar que a resistência média resultou em 2,05 $\pm 0,06 \mathrm{MPa}$ no corpo de prova de concreto referência $(0 \%)$, aumento de $11 \%$ com a adição de $5 \%$ de lodo e diminuição de $13 \%$ com a adição de $10 \%$ de 
lodo.

A análise estatística não possibilitou compreender o acréscimo de resistência e decréscimo na compressão diametral à medida em que os agregados da mistura foram substituídos. Isso é evidenciado pelo fato de não haver diferenças estatisticamente significativas entre as médias ( $95 \%$ de confiabilidade) após a análise por meio do intervalo de confiança.

A variação observada pode estar ligada ao processo de moldagem, tipo de cura e heterogeneidade no agregado [46]. Na Figura 5 são apresentados os resultados da absorção média de água sem ( $0 \%)$ e com a incorporação de $5 \%$ e $10 \%$ do lodo da ETA

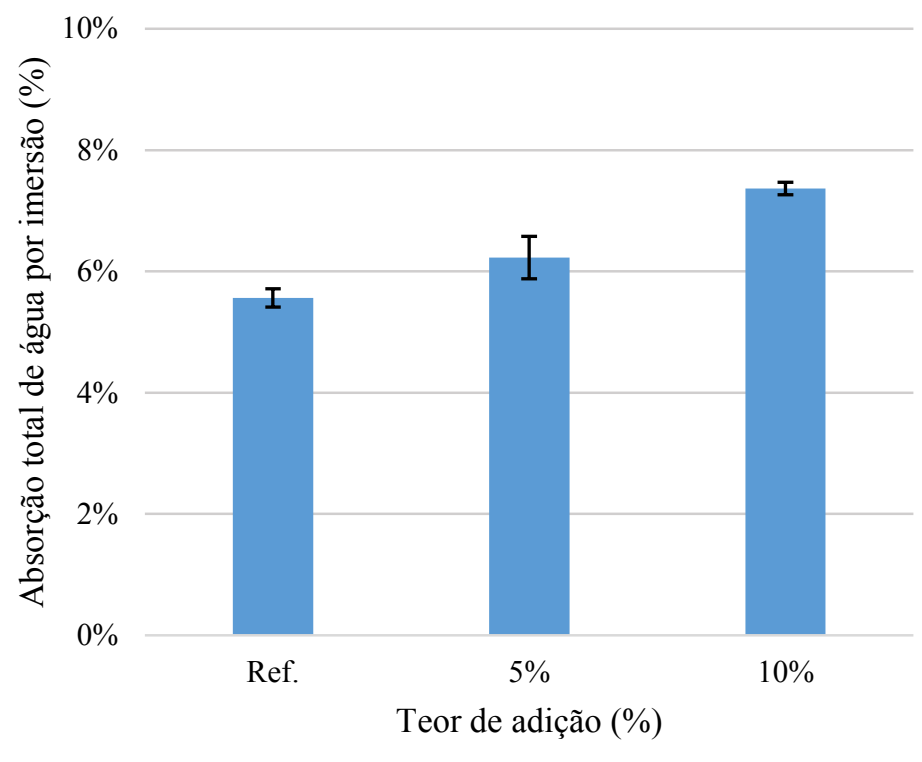

Figura 5: Variação da absorção total de água por imersão do concreto sem e com adição do lodo da ETA

Com a incorporação do lodo nos teores de 5\% e 10\%, a absorção de água aumentou em 12\% e 32\% em média, respectivamente.

SALES et al. [3] verificaram aumento de apenas $2 \%$ na absorção de água no concreto à medida que foram incorporados lodo de ETA e agregados reciclados. Nos resultados obtidos neste trabalho foram observadas diferenças significativas entre as médias com 99\% de confiabilidade apenas entre a amostra de referência e aquela com incorporação de $10 \%$ do lodo da ETA. As amostras com adição de $5 \%$ de lodo não apresentaram diferença estatisticamente significativa com as amostras de referência. Ainda com relação à absorção de água, o limite de absorção média de até $10 \%$ para concreto com agregado natural é estabelecido na ABNT NBR 6136 (2006) [47], e, portanto os resultados se enquadram nos limites estabelecidos. De acordo com GASPARIM [48], a durabilidade do concreto é inversamente proporcional à quantidade de absorção de água no corpo de prova, pois quanto maior a absorção maior será a possibilidade de ataques por agentes agressivos presentes na água.

À medida que o lodo da ETA foi incorporado no concreto, a absorção de água total aumentou gradativamente. Possivelmente, a ocorrência de tal fato seja pela reação expansiva gerada pelo ataque de sulfatos, que pode ter ocasionado microfissuras na amostra.

Outra possível causa é pela solubilização do material orgânico e outros compostos presentes no lodo que em contato com a água poderiam ter sido carreados das amostras, formando vazios dentro dos poros que posteriormente seriam preenchidos por água durante o ensaio de absorção de água. Estes poros estão ainda ligados à redução da durabilidade do material [49] por facilitarem a entrada de agentes agressivos e a carbonatação do concreto.

Desta forma, a absorção de água está diretamente ligada à porosidade do material (poros interconectados) e pode explicar a redução na resistência mecânica do material. Na Figura 6 é apresentada a correlação entre os resultados obtidos nos ensaios de absorção de água e resistência à compressão. 


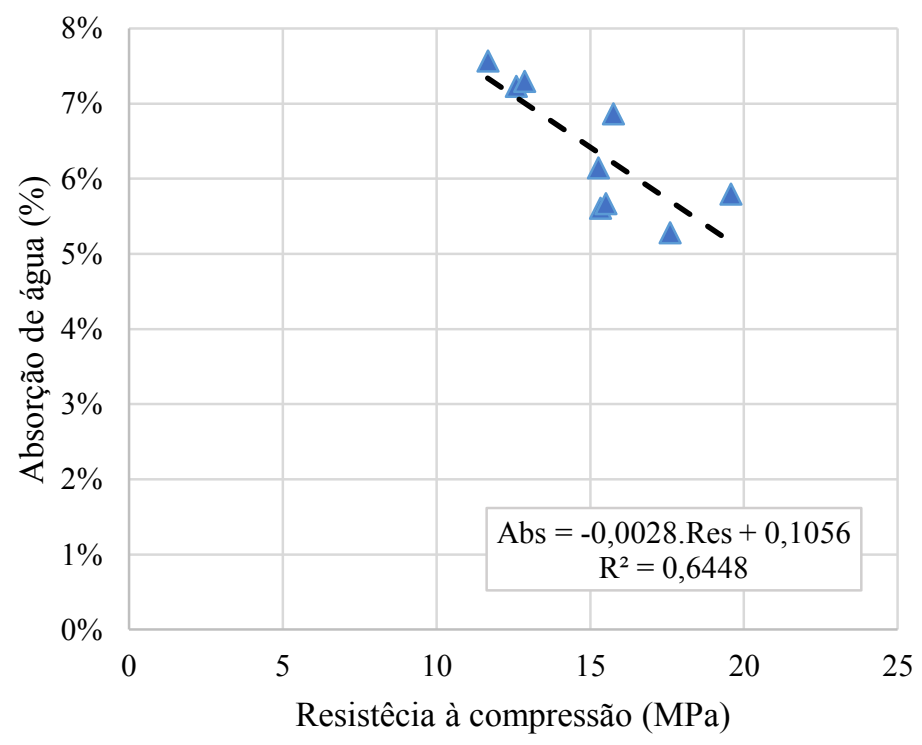

Figura 6: Correlação entre os resultados obtidos nos ensaios de compressão axial e absorção de água em amostras sem e com adição do lodo da ETA

Foi possível notar influência entre os resultados das análises realizadas $\left(R^{2}\right.$ de 0,6448$)$, mesmo com baixa correlação, estes resultados eram esperados, pela redução da área de distribuição de carga [50]. Outros autores $[51,52]$ observaram da mesma forma que a adição de lodo provenientes de estações de tratamento de água é capaz de contribuir com uma matriz cimentícia mais porosa e de menor resistência mecânica, podendo até inibir a ação de aditivos superplastificantes.

Na Tabela 5 é apresentada uma análise de variância dos ensaios realizados de forma a confirmar a influência da adição do lodo da ETA.

Tabela 5: Análise de variância (ANOVA) dos resultados obtidos.

\begin{tabular}{|c|c|c|c|c|c|c|c|}
\hline $\begin{array}{l}\text { Fonte da } \\
\text { variação }\end{array}$ & $\begin{array}{c}\text { Soma } \\
\text { quadrada }\end{array}$ & $\begin{array}{l}\text { Graus de } \\
\text { liberdade }\end{array}$ & $\begin{array}{c}\text { Média } \\
\text { quadrada }\end{array}$ & Teste F & F crítico & valor-p & Significativo? \\
\hline \multicolumn{8}{|c|}{ RESISTÊNCIA À COMPRESSÃO } \\
\hline Idade & 4,01 & 1 & 4,01 & 2,57 & 4,75 & 0,13500 & Não \\
\hline Adição & 102,98 & 2 & 51,49 & 32,95 & 3,89 & 0,00001 & Sim \\
\hline Interações & 3,89 & 2 & 1,95 & 1,25 & 3,89 & 0,32248 & Não \\
\hline Erro & 18,75 & 12 & 1,56 & & & & \\
\hline Total & 129,64 & 17 & & & & & \\
\hline \multicolumn{8}{|c|}{ RESISTÊNCIA À TRAÇÃO POR COMPRESSÃO DIAMETRAL } \\
\hline Adição & 0,35 & 2 & 0,18 & 12,84 & 5,14 & 0,00378 & Sim \\
\hline Erro & 0,08 & 6 & 0,01 & & & & \\
\hline Total & 0,43 & 8 & & & & & \\
\hline \multicolumn{8}{|c|}{ ABSORÇÃO DE ÁGUA POR IMERSÃO } \\
\hline Adição & 0,00050 & 2 & 0,00025 & 16,25 & 5,14 & 0,00680 & Sim \\
\hline Erro & 0,00009 & 6 & 0,00002 & & & & \\
\hline Total & 0,00059 & 8 & & & & & \\
\hline
\end{tabular}

A partir dos dados apresentados na Tabela 5 é possível observar que a incorporação do lodo de ETA gerou variação significativa nos resultados dos três ensaios realizados. Apesar da redução das propriedades mecânicas e aumento da porosidade, destaca-se que a adição deste resíduo em baixos teores não é capaz de causar influência significativa nas propriedades do estado endurecido do material $[51,52,53]$. Desta forma, a incorporação do lodo de estação de tratamento de água em compósitos cimentícios poderia se tornar uma opção viável de aproveitamento deste resíduo em peças de concreto sem fim estrutural: bloco intertravados para pavimento, concreto leve para preenchimento, tubulações de concreto, mobiliário urbano, dentre outros. 


\section{CONCLUSÕES}

Com os resultados obtidos com a incorporação do lodo da ETA em matriz de concreto, foi possível concluir que:

- As características físico-químicas do lodo gerado na ETA indicaram a inviabilidade de seu lançamento em corpos hídricos.

- A incorporação do lodo acarretou na redução da resistência do concreto com aumento da concentração do lodo. A adição de 5\% de lodo não indicou diferenças significativa na resistência axial em relação à amostra de referência. A incorporação de $10 \%$ indicou redução significativa na resistência à compressão, o que impossibilitaria sua incorporação em teores superiores.

- Não foram verificadas diferenças estatisticamente significativas nos resultados de resistência à tração por compressão diametral.

- A absorção de água nos corpos-de-prova aumentou proporcionalmente com a adição de lodo, com variação de $6 \%$ a $8 \%$, possivelmente ligada à redução da resistência mecânica do material.

Os resultados obtidos neste trabalho evidenciam a viabilidade de substituição do agregado miúdo pelo lodo da ETA em teores inferiores a 5\%. Desta forma, a incorporação deste resíduo em peças de concreto poderia ser uma solução viável à este passivo ambiental que hoje é descartado em corpos hídricos ou em aterros que na maioria das vezes não estão preparados para recebimento deste material.

\section{BIBLIOGRAFIA}

[1] SUKSIRIPATTANAPONG, C., HORPIBULSUK, S., BOONGRASAN, S., et al., "Unit weight, strength and microstructure of a water treatment sludge-fly ash lightweight cellular geopolymer", Construction and Building Materials, v. 94, pp. 807-816, 2015.

[2] AHMAD, T., AHMAD, K., ALAM, M. "Sustainable management of water treatment sludge through 3 'R' concept”, Journal of Cleaner Production, in press, pp. 1-13, 2016.

[3] CORDEIRO, J. S., "Importância do Tratamento e Disposição Adequada dos Lodos de ETAs”, In: Noções Gerais de Tratamento de Disposição Final de Lodos de ETA, Rio de Janeiro, ABES / PROSAB, pp. 1-19, 1999.

[4] ASSOCIAÇÃO BRASILEIRA DE NORMAS TÉCNICAS. NBR 10004:2014 - Resíduos sólidos - Classificação, Rio de Janeiro, 2014.

[5] BRASIL. Lei $\mathrm{n}^{0}$ 12305, de 02 de agosto de 2010. Institui a Política Nacional de Resíduos Sólidos; altera a Lei no 9.605, de 12 de fevereiro de 1998; e dá outras providências. Diário Oficial [da] União, Brasília, DF, 13 ago. 2010.

[6] BARBOSA, R. M., POVINELLI, J., ROCHA, O., et al., “A toxidade de despejos (lodos) de estações de tratamento de água à Daphnia Similis (Cladocera, Crustacea)”, In: Congresso Interamericano de Engenharia Sanitária e Ambiental, 27, Porto Alegre, 2000.

[7] PAULA, S. N., SOUZA, P. S. F., PEREIRA-FILHO, E. R., "Determinação de Cd e Pb: Avaliação de sedimentos do Rio Jundiaí-SP e Ribeirão Piraí-SP e lodo proveniente de uma Estação de Tratamento de Esgotos", Química Nova, v. 32, n. 9, p. 2367-2372, 2009.

[8] SALES, A., CORDEIRO, J. S., PALIARI, J. S., et al., "Utilização de Resíduos Gerados em Estações de Tratamento de Água em Argamassas e Concretos de Cimento Portland”, In: Congresso Brasileiro de Engenharia e Ciência dos Materiais, 15, Natal, 2002.

[9] HOPPEN, C. Reciclagem de lodo de ETA centrifugado na construção civil, método alternativo para preservação ambiental, Tese de D.Sc., Universidade Federal do Paraná, Curitiba, Brasil, 2004.

[10] HOPPEN, C., PORTELLA, K. F., ANDREOLI, C. V., et al., "Estudo de Dosagem para Incorporação de Lodo de ETA em Matriz de Concreto, como forma de Disposição Final”, In: Congresso Brasileiro De Engenharia Sanitária e Ambiental, 23, Campo Grande, 2005.

[11] RAMÍREZ ZAMORA, R. M., ESPEJEL AYALA, F., SOLÍS LÓPEZ, M., et al., "Optimisation and analysis of the synthesis of a cellular glass-ceramic produced from water purification sludge and clay", $A p$ plied Clay Science, v. 123, pp. 232-238, 2016.

[12] ANDREOLI, C. V., BERTOLDI, B., CARNEIRO, C.A., “A problemática da geração e disposição final de Lodo de ETA" In: Lodo de Estações de Tratamento de Água - Gestão e Perspectivas Tecnológicas, Curitiba, Sanepar, pp. 179-222, 2013. 
[13] EATON, A. D, CLESCERI, L. S, RICE, E. W., et al., Standard methods for the examination of water and wastewater, 21th ed. Washington: American Public Health Association, American water Works Association, Water Pollution Control Federation, 2005.

[14] ASSOCIAÇÃO BRASILEIRA DE NORMAS TÉCNICAS. NBR 6457:1986 - Amostras de solo - Preparação para ensaios de compactação e ensaios de caracterização. Rio de Janeiro. 1986.

[15] ASSOCIAÇÃO BRASILEIRA DE NORMAS TÉCNICAS. NBR 12076:1991 - Carvão ativado pulverizado - Determinação da massa específica aparente - Método de ensaio. Rio de Janeiro. 1991.

[16] ASSOCIAÇÃO BRASILEIRA DE NORMAS TÉCNICAS. NBR NM 52:2009 - Agregado miúdo - Determinação da massa específica e massa específica aparente. Rio de Janeiro. 2009.

[17] ASSOCIAÇÃO BRASILEIRA DE NORMAS TÉCNICAS. NBR NM 53:2009 - Agregado graúdo Determinação da massa específica, massa específica aparente e absorção de água. Rio de Janeiro. 2009.

[18] ASSOCIAÇÃO BRASILEIRA DE NORMAS TÉCNICAS. NBR NM 45:2006 - Agregados - Determinação da massa unitária e do volume de vazios. Rio de Janeiro. 2006.

[19] ASSOCIAÇÃO BRASILEIRA DE NORMAS TÉCNICAS. NBR NM 46:2003 - Agregados - Determinação do material fino que passa através da peneira 75 um, por lavagem. Rio de Janeiro. 2003.

[20] ASSOCIAÇÃO BRASILEIRA DE NORMAS TÉCNICAS. NBR NM 248:2003 - Agregados - Determinação da composição granulométrica. Rio de Janeiro. 2003.

[21] ASSOCIAÇÃO BRASILEIRA DE NORMAS TÉCNICAS. NBR 5738:2015 - Concreto - Procedimento para moldagem e cura de corpos de prova. Rio de Janeiro. 2015.

[22] ASSOCIAÇÃO BRASILEIRA DE NORMAS TÉCNICAS. NBR 5739:2007 - Concreto - Ensaios de compressão de corpos-de-prova cilíndricos. Rio de Janeiro. 2007.

[23] ASSOCIAÇÃO BRASILEIRA DE NORMAS TÉCNICAS. NBR 7222:2011 - Concreto e argamassa Determinação da resistência à tração por compressão diametral de corpos de prova cilíndricos. Rio de Janeiro. 2011.

[24] ASSOCIAÇÃO BRASILEIRA DE NORMAS TÉCNICAS. NBR 9778:2005 - Argamassa e concreto endurecidos - Determinação da absorção de água, índice de vazios e massa específica. Rio de Janeiro. 2005.

[25] ASSOCIAÇÃO BRASILEIRA DE NORMAS TÉCNICAS. NBR 9781:2013 - Peças de concreto para pavimentação - Especificação e métodos de ensaio. Rio de Janeiro. 2013.

[26] PORTELLA, K.F., ANDREOLI, C.V., HOPPEN, C., et al., "Caraterização físico-química do lodo centrifugado da estação de tratamento de água Passaúna - Curitiba - Pr", In: Congresso Brasileiro de Engenharia Sanitária Ambiental, 22, Joinville, 2003.

[27] ASSOCIAÇÃO BRASILEIRA DE NORMAS TÉCNICAS. NBR 15900:2009 - Água para amassamento do concreto. Rio de Janeiro. 2009.

[28] RICHTER, C. A., Tratamento de Lodo de Estação de Tratamento de Água, São Paulo, Editora Edgard Blücher Ltda, 2001.

[29] TSUTIYA, M. T., HIRATA, A. Y. “Aproveitamento e Disposição Final de Lodos de Estação de Tratamento de Água do Estado de São Paulo”, In: Congresso Brasileiro De Engenharia Sanitária E Ambiental, 21, João Pessoa, 2001.

[30] ASSOCIAÇÃO BRASILEIRA DE NORMAS TÉCNICAS. NBR 7215:1997 - Cimento Portland - Determinação da resistência à compressão. Rio de Janeiro. 1997.

[31] OLIVEIRA, N. S., Estudo da secagem de lodo de Estação de Tratamento de Água, Tese de D.Sc., Universidade Federal do Paraná, Curitiba, Brasil, 2010.

[32] CONSELHO NACIONAL DO MEIO AMBIENTE - CONAMA. Resolução n 357, de 17 de março de 2005. Dispõe sobre a classificação dos corpos de água e diretrizes ambientais para o seu enquadramento, bem como estabelece as condições e padrões de lançamento de efluentes, e dá outras providências. Diário Oficial [da] União, Brasília, DF, 18 mar. 2005, Seção 1, pp. 58-63.

[33] PARANÁ. SECRETARIA DE ESTADO DO MEIO AMBIENTE E RECURSOS HÍDRICOS. Resolução SEMA n ${ }^{\circ}$ 001/07, de 11 janeiro de 2007. Dispõe sobre licenciamento ambiental, estabelece condições e padrões ambientais e dá outras providências, para empreendimentos de saneamento. Diário Oficial do Estado do Paraná, PR, 23 jan. 2007, Edição 7395,p p. 1-81. 
[34] SOARES, L. A., Utilização do Resíduo de ETA no Tratamento de Efluente de Lagoas de Estabilização, Dissertação de M.Sc., Curso de Engenharia Civil, Programa de Pós Graduação Stricto Sensu em Engenharia do Meio Ambiente, Universidade Federal de Goiás, Goiânia, Brasil, 2013.

[35] ASSOCIAÇÃO BRASILEIRA DE NORMAS TÉCNICAS. NBR NM 137:1997 - Argamassa e concreto - Água para amassamento e cura de argamassa e concreto de cimento Portland. Rio de Janeiro. 1997.

[36] MACÊDO, A.N., LIMA, A.M., FONSECA, F. O., et al., "Análise estatística do comportamento mecânico à compressão do compósito cimento - madeira", Revista Matéria, Rio de Janeiro, v.16, n.2, 2011.

[37] PINHEIRO, B. C. A., ESTEVAO, G. M., SOUZA, D. P., "Lodo proveniente da estação de tratamento de água do município de Leopoldina, MG, para aproveitamento na indústria de cerâmica vermelha Parte I: caracterização do lodo", Revista Matéria, Rio de Janeiro, v. 19, n. 3, p. 204-211, Setembro, 2014.

[38] TUTIKIAN, B., HELENE, P., Dosagem dos concretos de cimento Portland. [s.1], IBRACON, 2011.

[39] MACIOSKI, G., Avaliação do comportamento de argamassas estabilizadas para revestimento, Trabalho Final de Curso, Engenharia Civil, Universidade Federal do Paraná, Curitiba, Brasil, 2014.

[40] SALES, A., SOUZA, F. R., ALMEIDA, F. C. R., "Mechanical properties of concrete produced with a composite of water treatment sludge and sawdust", Construction and Building Materials, v. 25, n. 6, pp. 2793-2798, 2011.

[41] BROWN, P. W., "Thaumasite formation and other forms of sulfate attack", Cement and Concrete Composites, v. 24, n. 3, pp. 301-303, 2002.

[42] SILVA, A. L. C., MACIOSKI, G., SOTO, N. T. A., et al., "Estudo da RAA em Agregados Artificiais da Região de Curitiba", In: 1 Encontro Luso-Brasileiro de Degradação em Estruturas de Concreto, Salvador, 2014.

[43] VIEIRA, C.M.F., MARGEM, J.I., MONTEIRO, S.N., “Alterações microestruturais de cerâmica argilosa incorporada com lodo de ETA”, Revista Matéria, Rio de Janeiro, v. 13, n. 2, pp. 275-281, 2008.

[44] KAKALI, G., TSIVILIS, S., SKAROPOULOU, A., et al., "Parameters affecting thaumasite formation in limestone cement mortar", Cement and Concrete Composites, v. 25, n. 8, pp. 977-981, 2003.

[45] BROWN, P., HOOTON, R.D., CLARK, B, "Microstructural changes in concretes with sulfate exposure", Cement and Concrete Composites, v. 26, n. 8, p. 993-999, 2004.

[46] MEHTA, P. K., MONTEIRO, P. J. M., Concreto: Estruturas, Propriedades e Materiais, São Paulo, Pini, 1994.

[47] ASSOCIAÇÃO BRASILEIRA DE NORMAS TÉCNICAS. NBR 6136:2014 - Blocos vazados de concreto simples para alvenaria - Requisitos. Rio de Janeiro, 2014.

[48] GASPARIM, J. C., Concreto projetado elaborado com cimentos especiais: análise segundo parâmetro de durabilidade, Dissertação de M.Sc., Engenharia de Construção Civil e Urbana, Universidade de São Paulo, São Paulo, Brasil, 2007.

[49] POSSER, N. D. Proporcionamento de Argamassa para Reboco de Recuperação, Trabalho de Especialização em Engenharia Civil, Universidade Federal do Rio Grande do Sul, Porto Alegre, Brasil, 2004.

[50] CHATVEERA, B. LERTWATTANARUK, P. MAKUL, N., "Effect of sludge water from ready-mixed concrete plant on properties and durability of concrete", Cement and Concrete Composites, v. 28, n. 5, pp. 441-450, 2006.

[51] CHATVEERA, B. LERTWATTANARUK, P., "Use of ready-mixed concrete plant sludge water in concrete containing an additive or admixture", Journal of Environmental Management, v. 90, n. 5, pp. 19011908, 2009.

[52] YAGÜE, A., VALLS, S., VÁZQUEZ, E., et al., "Durability of concrete with addition of dry sludge from waste water treatment plants", Cement and Concrete Research, v. 35, n. 6, pp. 1064-1073, 2005.

[53] VALLS, S., YAGÜE, A., VÁZQUEZ, E., et al., "Physical and mechanical properties of concrete with added dry sludge from a sewage treatment plant", Cement and Concrete Research, v. 34, n. 12, pp. 22032208, 2004. 